\title{
Airborne hyperspectral imaging for investigating the dynamics of alternate bearing in citrus
}

\author{
Xujun $\mathrm{Ye}^{1)}$, Kenshi Sakai*1), Shin-Ichi Asada ${ }^{2)}$, Tetsuya Akita $^{1)}$ and \\ Akira Sasao $^{1)}$
}

\author{
${ }^{1)}$ Faculty of Agriculture, Tokyo University of Agriculture and Technology, Tokyo 183-8509, Japan \\ ${ }^{2)}$ Nebukawa Prefectural Agricultural Research Institute, Kanagawa 250-0024, Japan
}

\begin{abstract}
An Airborne Imaging Spectrometer for Applications (AISA) system was used to obtain hyperspectral images over an experimental citrus orchard located at Nebukawa Agricultural Research Station, Japan during the months of April, May and June in 2003. The objective was to determine to what extent the reflectances in the 72 visible and near-infrared (NIR) wavelengths (from 407 to $898 \mathrm{~nm}$ ) obtained in different months might be related to differences in fruit yield of citrus trees. Multiple linear regression and neural network algorithms were employed to develop yield prediction models. Correlation Coefficient Analysis (CCA), Principal Component Analysis (PCA) and Partial Least Squares (PLS) regression were used to reduce the number of input variables. Results indicated that the PLS method performed the best in extracting predictor factors that have a high correlation with citrus yield, followed by the CCA method. However, the PCA method did not yield a satisfactory result. The performance of neural network models was further verified by statistical analysis of the ensemble ten thousand models developed with random initialization of training parameters. It is demonstrated that there is a more evident correlation between the spectral characteristics in May and the citrus yield, compared to those in April and June.
\end{abstract}

\section{Keywords}

remote sensing, hyperspectral imaging, multiple linear regression, neural network algorithms, principal component analysis (PCA), partial least squares regression (PLS), citrus

\section{Introduction}

Alternate bearing is a within-field yield variability phenomenon that is quite common among tree crops. It is an important characteristic of tree crops such as citrus, apples, and nuts. A number of hypotheses have been proposed to explain this phenomenon, among which the so-called resource budget model proposed by Isagi has been widely used (Isagi, 1995; Isagi et al., 1997; Sakai, 2001; Noguchi et al., 2003).

The resource budget model describes a deterministic processing of internal resources, including " Corresponding author. Tel/fax: +81-42-367-5755. E-mail: ken@cc.tuat.ac.jp (Kenshi Sakai) energy accumulation as a result of photosynthesis and energy depletion due to flower and fruit production (Isagi, 1995; Isagi et al., 1997). It was assumed that each tree accumulates photosynthate every year, producing flowers when energy reserves exceed a threshold level, and sets fruits at a rate limited by the ratio between the cost of flowering and fruiting in individual plants. After a major reproductive event, energy reserves will be depleted and it may take one year or several years before levels once more attain the level required for reproduction. The temporal variability of fruit yields in individual trees as a result of this mechanism leads to fluctuations in fruit production between one year and 
another. This has become a challenge for agriculture as the uncertainty in fruit yields makes it difficult to make proper marketing plans, which normally needs to be done before the harvest season.

Sakai et al. (2003) and Noguchi et al. (2003) reported a way to reconstruct the dynamics of alternate bearing by response surface methodology and Jacobian Matrix calculated from a very short ensemble data of 3 to 5 years of measurements on 50 to 96 individual citrus trees. They also showed the possibility of one-year forward prediction of fruit yields on an individual tree basis. However, in order to apply this methodology, an individual tree's yield and/or fruit number must be obtained or estimated, which is impossible in practical situations.

In recent years, remote sensing technology has been used as an effective tool to obtain and map factors influencing farm productivity. Different remote sensing applications have proved to be a potential source of reflectance data for estimation of several canopy variables related to biophysical, physiological or biochemical characteristics (Ahlrichs \& Bauer, 1983; Wiegand et al., 1992; Yoder \& Waring, 1994; Serrano et al., 2000; Thenkabail et al., 2001). Many relationships between the spectral response of crops and growth factors have been elucidated, based on reflectances obtained from ground-based and aircraft-mounted sensors acquiring images in the visible (RGB) and infrared spectrum (Curran et al., 1990, 1991 \& 2001; Jago et al., 1999; Zhang et al., 1997 \& 2002).

This research set out to examine the hypothesis that there is a correlation between the canopy structural features and citrus yield. The canopy structural features were identified from airborne hyperspectral remote sensing images. The objectives were: (1) to identify the best season for acquiring images that can be used to best estimate citrus yield; and (2) to develop an effective methodology for developing prediction models based on the hyperspectral images.

\section{Materials and methods}

\section{Experimental area}

The experimental citrus orchard is located at Kanagawa Agricultural Research Station, Kanagawa
Prefecture in Japan (139 07'44.29" East and $35^{\circ} 12^{\prime} 13.01^{\prime \prime}$ North). The citrus variety is Satsuma Mandarin, a native citrus variety in southeastern Asia that is being abundantly grown in Japan. The trees are grown in an area of $2,700 \mathrm{~m}^{2}$ with a slope of about 40 degrees (Fig. 1).

\section{Image acquisition and data extraction}

Airborne hyperspectral images with $1.5 \mathrm{~m}$ spatial resolution, 72 channels (from $407 \mathrm{~nm}$ to 898 $\mathrm{nm}$ ) and $6.3 \mathrm{~nm}$ spectral resolution were collected using an Airborne Imaging Spectrometer for Applications (AISA) spectrometer over the study site in 3 consecutive months, on April 10, May 21 and June 5, 2003. Hyperspectral data were processed to at-sensor radiance using calibration coefficients derived in the laboratory by Pasco Corporation, Japan. The data were then converted to reflectance to eliminate atmospheric effects and compensate for changes in solar illumination during image acquisition. Reflectance data were geo-referenced using GPS data collected onboard the aircraft. Yield data on individual citrus trees were collected during the local harvest season in 2003. Preliminary experiments were conducted in a plot having 48 citrus trees of the same variety type and of the same age (Fig. 1b).

Based on the three hyperspectral images (April, May and June, 2003), the average reflectance at each wavelength for each canopy was extracted with the aid of Erdas IMAGINE 8.6. Fig. 2 shows the average reflectance characteristics of all canopies in different months. The April average reflectances of all wavelengths were lower than those of May and June. This was due to the fact that in May and June the vigorous growing of new leaves and heavy blossoming of flowers produced more spectral-sensitive light green new leaves and white flora buds in citrus canopies, contributing to the increase in spectral reflectances at all wavelengths, while in April those new leaves were still not growing fast and flowers were not blossoming heavily. In addition, the June average reflectances of all wavelengths appear to be slightly lower than those of May, indicating that the light green new leaves started 


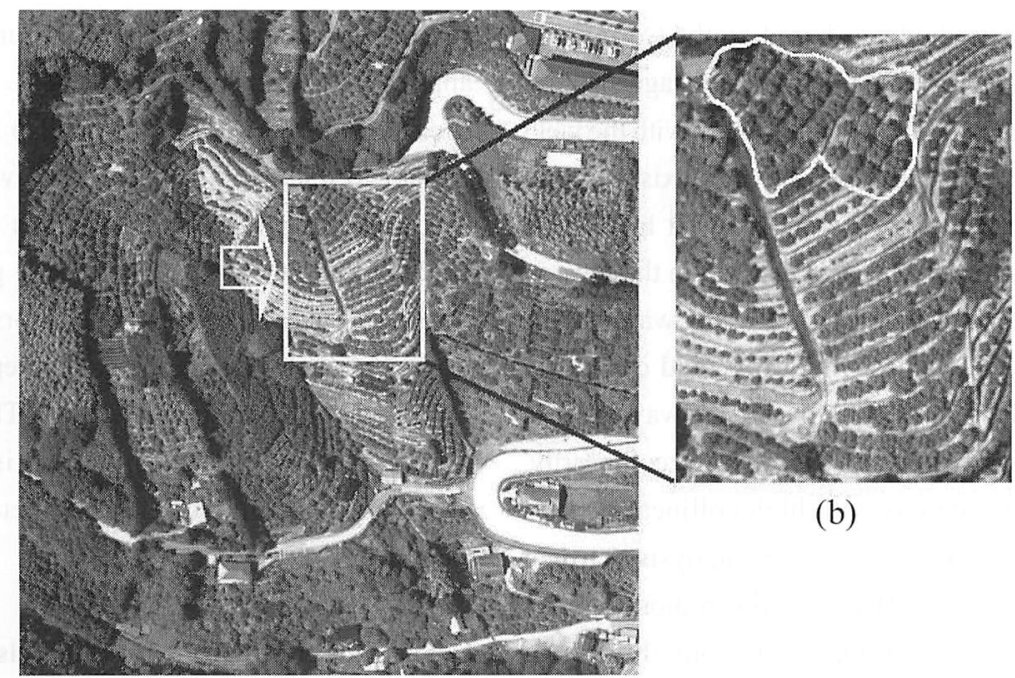

(a)

Fig. 1. (a) The experimental citrus orchard at Kanagawa Agricultural Research Station, Kanagawa Prefecture in Japan. (b) Location of forty-eight trees of same variety and age category used in the study.

to turn darker as the accumulation of reserves in leaves increased as a result of photosynthesis, and the flowers slightly decreased after the heavy blossoming in May.

\section{Methods to determine predictor factors}

One difficulty in hyperspectral data analysis is the problem of processing an extremely large quantity of data obtained from too many wavelengths. The so-called multicollinearity problem easily occurs in hyperspectral data because high correlations may exist between present wavelengths, particularly adjacent ones. When the number of predictor variables to be estimated is larger than the number of samples, the high multicollinearity makes the model training procedure more difficult, and the resulting model is thus overfitted due to a lack of degrees of freedom. Because there are more predictor variables than samples in this study ( 72 wavelengths and 48 samples), some statistical processing is necessary to eliminate the redundant variables before proceeding to the modeling process. The objective of the statistical processing was to find factors that best contribute to the prediction of citrus yield. Several methods were used to determine these factors as follows:

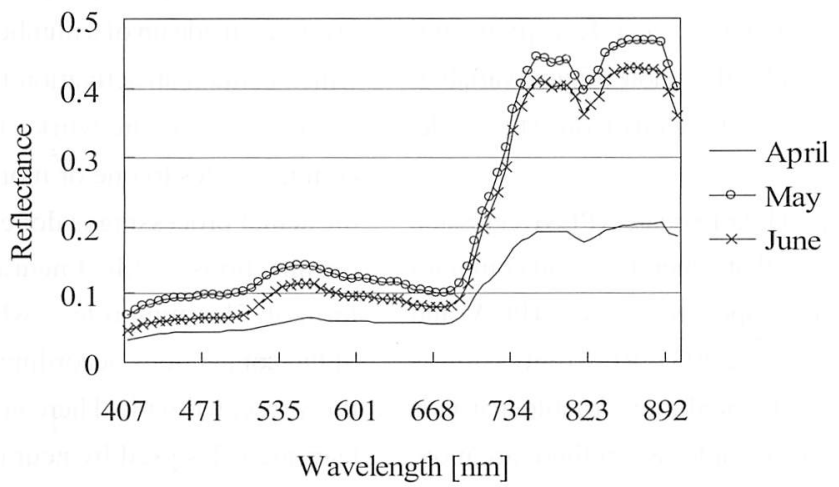

Fig. 2. Average spectral characteristics of forty-eight tree canopies in April, May and June 2003 
The first method was based on the Correlation Coefficient Analysis (CCA) between average spectral reflectance of canopies at each wavelength with the yield of the citrus samples. As collinearity may exist between adjacent wavelengths, wavelengths that have high correlations with citrus yield may appear in the form of some wavelength regions. Simply selecting wavelengths that are highly correlated with citrus yield can easily result in the selection of a set of similar wavelengths with high collinearity. In order to reduce the collinearity, some wavelength regions with high collinearity were pre-identified by simple correlation analysis between individual wavelengths. Wavelengths in those regions were considered as having equal contribution to calibration models, and only the wavelength that had the highest correlation with citrus yield within each wavelength region was selected as a predictor factor.

The second method was the Principal Component Analysis (PCA), which is an effective technique for eliminating the multicollinearity problem, by making 'pseudo' variables (so-called principal components) from linear combinations of the original predictor variables. This technique has three effects: it orthogonalizes the components of the predictor variables so that they are uncorrelated with each other; it orders the resulting orthogonal components so that those with the largest variation come first; and it eliminates those components which contribute the least to the variation in the dataset (Ramadan et al., 2004). In most cases, two principal components are sufficient to explain more than $80 \%$ of the variation in the original variables, resulting in considerable compression of the data. Therefore, application of a few principal components' scores instead of the whole original variables as the predictor variables can efficiently reduce the model architecture.

Finally, the Partial Least Squares (PLS) regression was used. It is a technique that generalizes and combines features from Principal Component Analysis (PCA) and multiple regression (Abdi, 2003). PLS regression is particularly useful when the predictor variable matrix is poorly conditioned (for example, when there are more variables than samples). It is one of the standard calibration methods commonly used in many chemical applications (Ramadan et al., 2004). The PLS model tries to find a few PLS factors (also known as latent variables) that explain most of the variation in both predictors and responses. Factors that accurately explain response variation provide good predictive models for new responses, and factors that accurately explain predictor variation are well represented by the observed values of the predictors. The Partial Least Squares (PLS) regression method is well suited to problems with multicollinear predictor and response variables.

\section{Development of calibration models}

The wavelengths that have the highest correlation with citrus yield within each wavelength region determined by CCA, the principal components extracted by PCA and the latent variables extracted by PLS were used as predictor factors to test their prediction performance. Multiple linear regression and neural network algorithms were employed to develop calibration models.

The purpose of multiple linear regression is to establish a quantitative relationship between a group of predictor variables and a response variable. It is an extension of the simple linear regression from a single dimension to multiple ones.

Neural network algorithms have been widely used in modeling a variety of nonlinear behaviors (Bischof et al., 1992; Atkinson \& Tatnall, 1997; Keiner \& Yan, 1998; Mutanga \& Skidmore, 2004). Neural networks are typically organized in layers where these layers are made up of a number of interconnected nodes, which contain an activation function. Input vectors are presented to the network via the input layer, which communicates to one or more 'hidden layers' where the actual processing is done via a system of weighted 'connections' . Most neural networks contain some form of 'learning rule', which modifies the weights of the connections according to the input patterns that it is presented with. There are many different kinds of learning rules used by neural networks; in this study, the most commonly used backpropagation algorithm 
was employed to train the neural network.

A three-layer network architecture, consisting of one input layer, one hidden layer and one output layer, was established. The predetermined predictor factors were used as inputs in the input layer. The hidden layer contains five neurons, each receiving data information from the input layer. As only the citrus yield was used as the target in the network, the output layer contains only one neuron. The early stopping technique was incorporated into the training of the network in order to overcome the overfitting problem and thus improve the network generalization.

Because the neural network parameters are randomly initialized during the training process, the same settings of training criteria (such as the maximum number of iterations or the minimum mean square of errors (MSE), etc.) usually would result in models with significantly varying fitting results. Therefore, 10,000 ensemble training experiments were carried out to create neural network models for each of the three hyperspectral data (April, May and June, 2003). The best fit model was then identified for each of the three hyperspectral data.

\section{Data preparation}

In this study different methods of data preparation were used for multiple linear regression and neural network models development. Before categorizing the data, the whole dataset was arranged in ascending order according to the yield, and then divided into two parts at alternate intervals. The first part consisting of data corresponding to 24 tree samples (half of the whole dataset) was used as a training dataset for developing both the multiple linear regression models and the neural network models. The remaining dataset consisting of data corresponding to 24 tree samples was used as a validation dataset for the multiple linear regression models, but it was further separated into two subsets for the case of the neural network models (each onefourth of the whole dataset). One subset consisting of data corresponding to 12 tree samples was used to monitor the network performance during the training process for improving the network generalization by the early stopping technique, and the other one consisting of data corresponding to 12 tree samples was used for validation of the trained models.

\section{Results and discussion}

\section{Statistical analysis results}

Fig. 3 shows the generated image of the matrix of correlation coefficients calculated by simple correlation analysis between individual wavelengths. It is clear that the wavelengths could be separated into four regions, which correspond to the common $\mathrm{R}, \mathrm{G}, \mathrm{B}$ and NIR regions. These four wavelength regions, namely

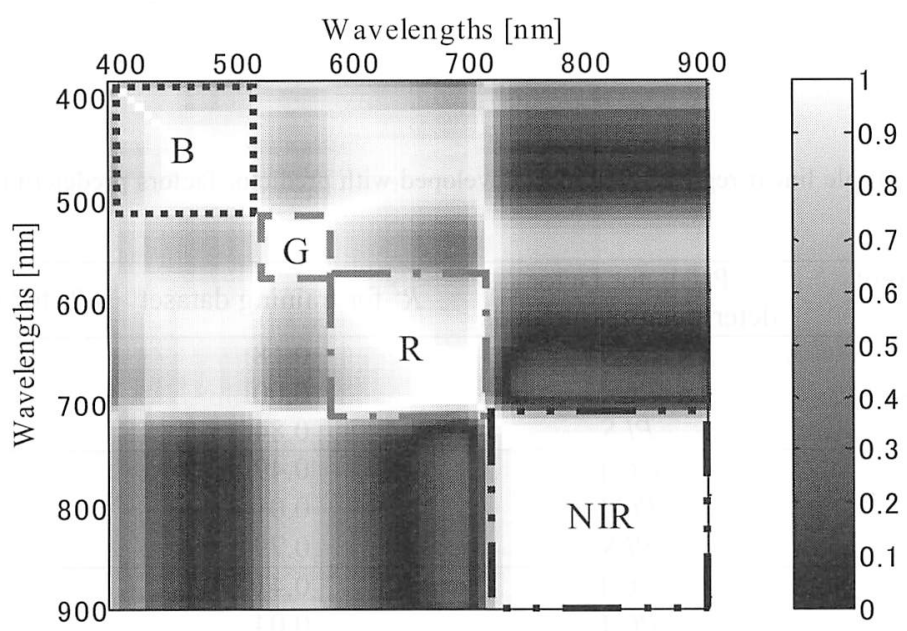

Fig. 3. Generated image of the matrix of correlation coefficients among individual wavelengths 
$407-522 \mathrm{~nm}, 522-580 \mathrm{~nm}, 580-714 \mathrm{~nm}$, and $714-898 \mathrm{~nm}$, were identified as marked by the vertical dotted lines in Fig. 4. Wavelengths within each region were highly correlated with a correlation coefficient of more than 0.9. Fig. 4 also shows the correlation coefficient spectra between canopy average spectral reflectance at each wavelength and the citrus yield of the samples. Individual wavelength was found to be poorly correlated with the citrus yield. Four wavelengths, each having the highest correlation coefficient with citrus yield within the region to which it belongs, were selected as predictor factors for each of the three hyperspectral data.

A PCA was performed for each of the three wavelength matrixes. The first two principal components for all the three matrixes were found to have a sum of variation exceeding $97 \%$ of the original dataset $(98.37 \%$, $\mathbf{9 7 . 5 0 \%}$ and $97.85 \%$ for April, May and June data, respectively), and thus were used to represent the original dataset as predictor factors.

The PLS procedure extracted latent variables for each of the three hyperspectral data. The first three latent variables accounted for more than $98 \%$ of the predictor variation for all the three hyperspectral data, similar to the effects of the first two principal components extracted by PCA. However, the response variation explained by these three PLS latent variables was only $23.96 \%, 36.74 \%$ and $50.18 \%$, respectively. A total of the first seven latent variables accounted for

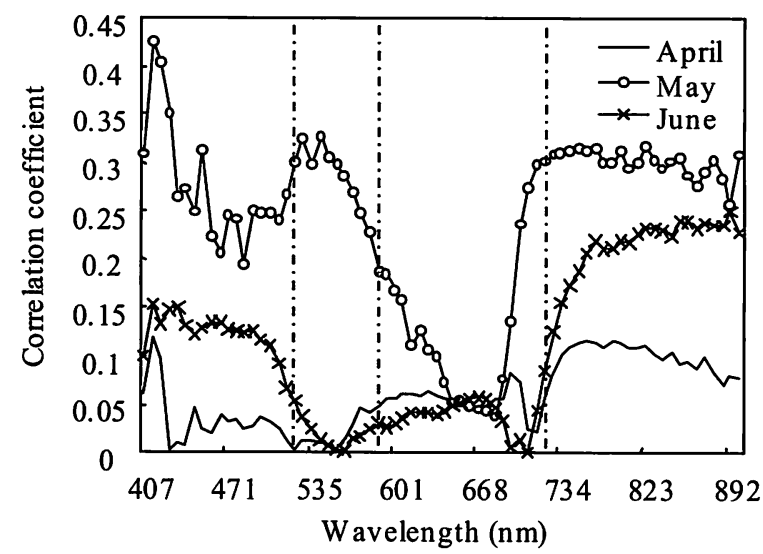

Fig. 4. Correlation coefficient spectrum between individual wavelength and citrus yield

Table 1. Results of multiple linear regression models developed with predictor factors predetermined by three different methods

\begin{tabular}{cccc}
\hline $\begin{array}{c}\text { Models for different } \\
\text { month data }\end{array}$ & $\begin{array}{c}\text { Predictor factor } \\
\text { determination methods }\end{array}$ & $R^{2}$ for training dataset & $R^{2}$ for validation dataset \\
\hline \multirow{3}{*}{ April models } & $C C A$ & 0.18 & 0.01 \\
& $P C A$ & 0.00 & 0.01 \\
& $P L S$ & 0.84 & 0.33 \\
\hline \multirow{3}{*}{ May models } & $C C A$ & 0.49 & 0.12 \\
& $P C A$ & 0.01 & 0.01 \\
& $P L S$ & 0.79 & 0.39 \\
\hline \multirow{2}{*}{ June models } & $C C A$ & 0.41 & 0.00 \\
& $P C A$ & 0.04 & 0.00 \\
\hline
\end{tabular}


Table 2. Results of the best fit neural network models developed with predictor factors predetermined by three different methods

\begin{tabular}{ccccc}
\hline $\begin{array}{c}\text { Models for } \\
\text { different month } \\
\text { data }\end{array}$ & $\begin{array}{c}\text { Predictor factor } \\
\text { determination methods }\end{array}$ & $\begin{array}{c}R^{2} \text { for training } \\
\text { dataset }\end{array}$ & $\begin{array}{c}R^{2} \text { for early } \\
\text { stopping dataset }\end{array}$ & $\begin{array}{c}R^{2} \text { for validation } \\
\text { dataset }\end{array}$ \\
\hline \multirow{3}{*}{ April models } & $C C A$ & 0.67 & 0.52 & 0.51 \\
& $P C A$ & 0.47 & 0.05 & 0.09 \\
& $P L S$ & 0.84 & 0.70 & 0.65 \\
\hline \multirow{3}{*}{ May models } & $C C A$ & 0.57 & 0.55 & 0.49 \\
& $P C A$ & 0.64 & 0.34 & 0.41 \\
& $P L S$ & 0.83 & 0.77 & 0.78 \\
\hline \multirow{3}{*}{ June models } & $C C A$ & 0.56 & 0.12 & 0.03 \\
& $P C A$ & 0.80 & 0.29 & 0.14 \\
\hline
\end{tabular}

$78.70 \%, 79.08 \%$ and $87.60 \%$ of the response variation for the April, May and June hyperspectral data, respectively. Therefore, these seven latent variables for each wavelength matrix were selected as predictor factors for the three hyperspectral data.

\section{Multiple linear regression models}

Table 1 shows the $R^{2}$ values for the linear regression between the actual yield and the predicted values by different multiple linear regression models. Although CCA and PCA methods were employed to reduce the collinearity of the training dataset, the performance of these two procedures was not satisfactory. In contrast, the results of the PLS method show a better relationship between the actual yield and the predicted values on both the training dataset and the validation dataset. Comparison of the PLS model results between different month models showed that the model corresponding to the May hyperspectral data achieved the best result.

\section{Neural network models}

The best fit model was identified among the 10,000 ensemble neural network models developed for each of the three hyperspectral data. Simple linear regression analyses between the network outputs and the corresponding actual yields were performed on the training dataset, the early stopping dataset and the validation dataset, respectively, and the results were as listed in Table 2.

The results showed an improvement of the models using neural network algorithms in modeling the relationship between hyperspectral data and citrus yield. Models corresponding to the May hyperspectral data all showed the best results, regardless of the different predictor factor determination methods employed. Similar to the previous multiple linear regression results, the PLS models also showed a better relationship between the actual citrus yield and the predicted values on all the three datasets, compared to the models developed with predictor factors extracted by the other two methods. The PLS model corresponding to the May hyperspectral data was particularly satisfactory. The $R^{2}$ values for the training dataset were 0.83 , and 0.77 and 0.78 for the early stopping and validation datasets (Fig. 5). These results suggest that the combined application of the PLS method and neural network algorithms performs the best in creating calibration models, and that the spectral reflectance features in May have the highest correlation with the actual citrus yields.

To confirm the results of the best fit neural network model analysis, the 10,000 ensemble trained neural network models for individual hyperspectral data were further analyzed and compared in terms of the coefficient of determination $\left(R^{2}\right)$ and the relative root mean square of error (RRMSE). $R^{2}$ is the most commonly 

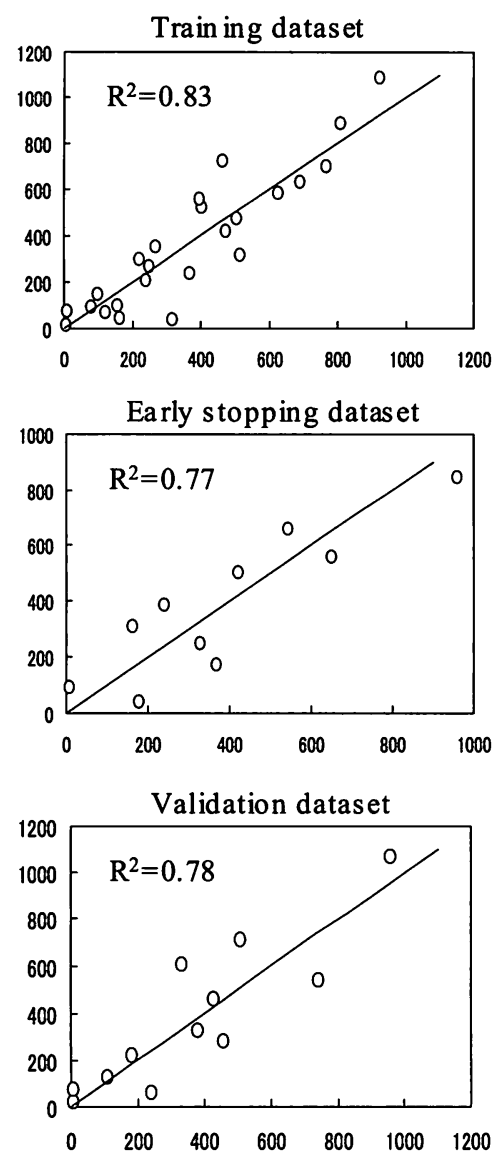

\section{$\mathrm{X}:$ Pred icted value $\longrightarrow \mathrm{Y}=\mathrm{X}$ Y: Actual yield}

Fig. 5. Predicted results of the PLS neural network model corresponding to the May hyperspectral data

used indicator for evaluating model accuracy, and RRMSE is an extended form based on the root mean square of error (RMSE), which is calculated as in Eq. (1):

$$
R R M S E=\frac{\sqrt{\frac{1}{N} \sum_{i=1}^{N}[X(i)-Y(i)]^{2}}}{\sqrt{\left.\frac{1}{N} \sum_{i=1}^{N}[X(i)-\bar{X})\right]^{2}}}
$$

where $X(i)$ is the actual values, $\bar{X}$ is the average of the actual values, and $Y(i)$ is the predicted values. Statistically, it is often suggested that the best fit model should be identified as the one with the largest $R^{2}$, but with the least RRMSE.

Firstly, a two-way ANOVA with interaction effects for the ensemble models was used to examine the responses of these two indicators to the image acquisition date (April, May and June) and the predictor factor determination methods (CCA, PCA and PLS). Both $R^{2}$ and $R R M S E$ values differed significantly among image acquisition dates and predictor factor determination methods. A significant difference in interaction effect between image acquisition dates and predictor factor determination methods was also detected (Table 3).

Table 3. Two-way ANOVA results for comparisons of the $R^{2}$ and $R R M S E$ values for the validation dataset

\begin{tabular}{cccc}
\hline & \multicolumn{3}{c}{ ANOVA (F-statistic) } \\
\cline { 2 - 4 } & Month & Method & $\begin{array}{c}\text { Month } \times \\
\text { Method }\end{array}$ \\
\hline$R^{2}$ & $1056.56^{* *}$ & $1784.18^{* *}$ & $490.98^{* *}$ \\
$R R M S E$ & $3474.2^{* *}$ & $4808.06^{* *}$ & $1386.56^{* *}$ \\
\hline
\end{tabular}

*.Significant at 0.01 .

Secondly, the frequency distribution of $R^{2}$ and RRMSE values was used to identify the best model development scenario. Fig. 6 and Fig. 7 show the frequency distribution of $R^{2}$ and $R R M S E$ values for the validation datasets, respectively. Comparison of the results for the models developed with the same data revealed that the PLS method achieved the largest number of models with better prediction performance (the number in the higher $R^{2}$ and lower RRMSE value regions), followed by the CCA method, and the PCA method was the least. The poor performance of the PCA method in this analysis could be attributed to the fact that the extracted principal components were only chosen to explain the predictor variables rather than the response variable, and thus those principal components which explain the predictor variables were not necessarily relevant for the response variable. In contrast, the PLS method performed much better because it involved the correlation between the predictor variables and the response variable while 


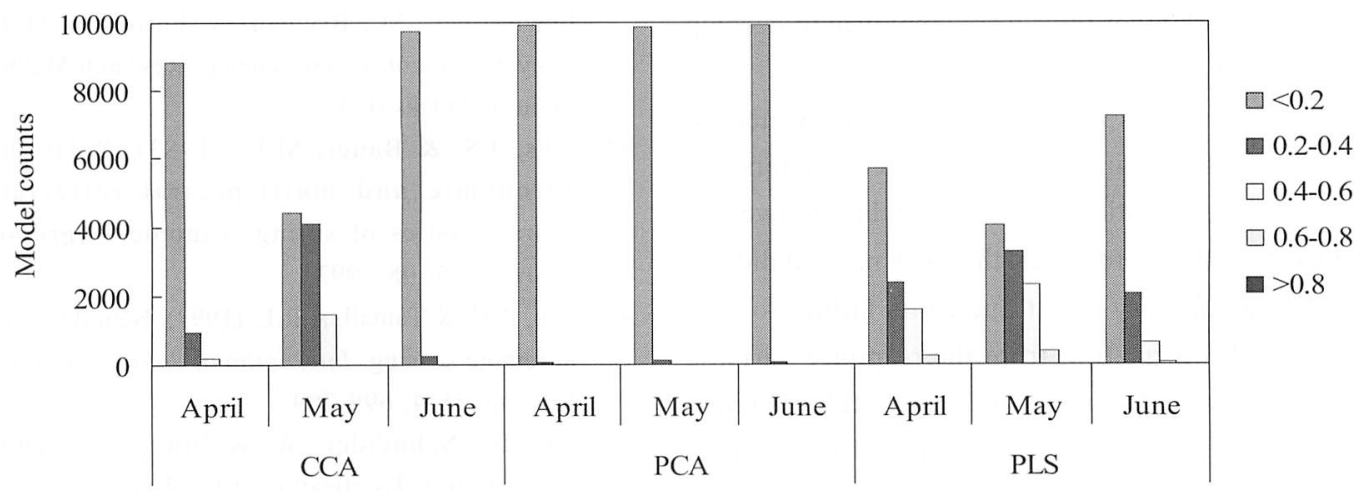

Fig. 6. Frequency distribution of the $R^{2}$ for the validation dataset

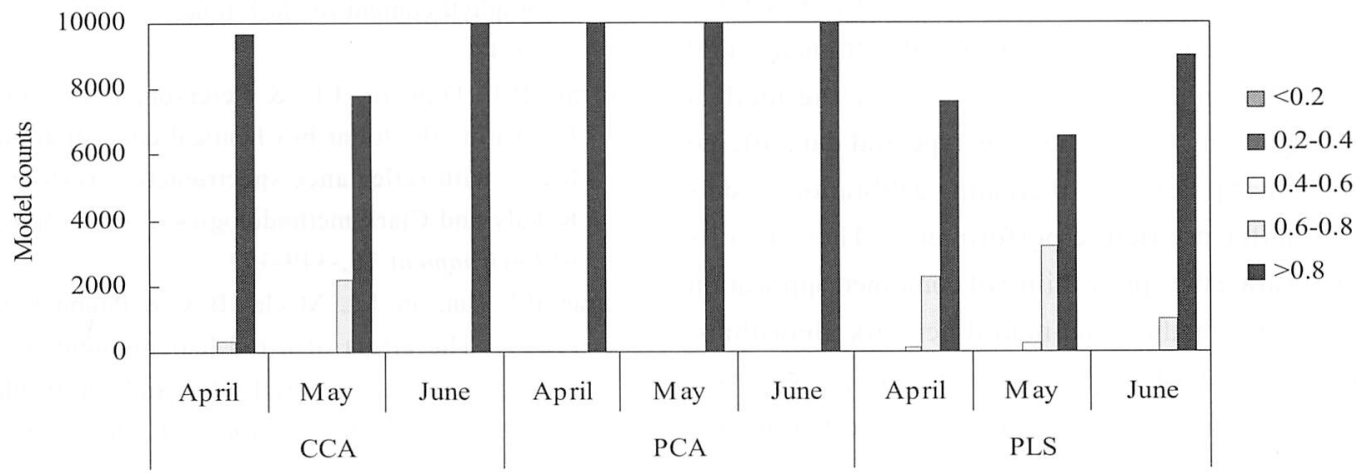

Fig. 7. Frequency distribution of the RRMSE for the validation dataset

extracting the latent variables, and it was also possible to select a suitable number of predictor factors according to the accumulated variation percentage of both the predictor and response variations explained by them.

Comparison of the models developed with different month's data indicated that the May hyperspectral data has the highest possibility of creating good calibration models. These results confirmed the previous best fit model analysis results, showing the existence of more significant correlations between the May hyperspectral data and citrus yield in the study area.

\section{Conclusions}

This research was conducted as a preliminary step for developing a methodology for predicting the yield of citrus trees. Hyperspectral images of the citrus orchard were acquired using an AISA airborne spectrographic imager by Pasco Company, Japan. Average spectral reflectances of wavelengths from 407 $\mathrm{nm}$ to $898 \mathrm{~nm}$ for the canopies of selected tree samples were extracted with the aid of Erdas IMAGINE 8.6 software. Correlation Coefficient Analysis (CCA), Principal Component Analysis (PCA) and Partial Least Squares (PLS) regression methods were used to determine predictor factors due to high multicollinearity in the original dataset. Multiple linear regression and 
neural network algorithms were employed to develop calibration models.

The results indicated that the PLS method performed the best in extracting predictor factors that have a high correlation with citrus yield, followed by the CCA method. However, the PCA method did not yield a satisfactory result due to its failure to take account of information from the response variable while extracting the predictor factors. Multiple linear regression models could not predict citrus yield as accurately as neural network models did. Comparisons of the various model performances further revealed that the models corresponding to the May hyperspectral data predicted citrus yield more accurately than those collected in April and June. Statistical analysis of 10,000 ensemble trained neural network models also confirmed that the models corresponding to the May hyperspectral data offered the highest possibility of creating calibration models with better predictive performance. These results demonstrate the applicability of combined application of the PLS method and neural network algorithms, and suggest the relevance of canopy spectral reflectance features in May rather than other months in exploring the potential of airborne hyperspectral imaging for predicting citrus yield.

The methodology proposed in this paper of creating calibration models for predicting citrus yield from hyperspectral data is considered to be very promising, although further research is needed before these models can be applied to a practical situation.

\section{Acknowledgements}

This research was funded by Japanese Society for the Promotion of Science grant-in-aid for scientific research nos. 2110, 14360148 and 15658074 . We would like to gratefully acknowledge Dr. Bhuweneshwar P. Sah and Mr. Suhama of Pasco Corporation for the acquisition of the hyperspectral images.

\section{References}

Abdi,H, (2003). Partial least squares (PLS) regression. In:
Lewis-Beck, M., Bryman, A, Futing, T. (Eds.). Encyclopedia of Social Sciences Research Methods. Thousand Oaks (CA): Sage.

Ahlrichs, J.S. \& Bauer, M.E. (1983). Relation of agronomic and multispectral reflectance characteristics of spring canopies. Agronomy Journal, 75, 987-993.

Atkinson, P.M. \& Tatnall, A.R.L. (1997). Neural networks in remote sensing. International Journal of Remote Sensing, 18 4, 699-709.

Bischof, H., Schneider, W. \& Pinz, A.J. (1992). Multispectral classification of Landsat- images using neural networks. IEEE Transactions on Geoscience and Remote Sensing, 30, 482-490.

Curran, P.J., Dungan, J.L. \& Gholtz, H.L. (1990). Exploring the relationship between reflectance red edge and chlorophyll content of slash pine. Tree Physiology, 7, 33-48.

Curran, P.J., Dungan, J.L. \& Peterson, D.L. (2001). Estimating the foliar biochemical concentration of leaves with reflectance spectrometry: Testing the Kokaly and Clark methodologies. Remote Sensing of Environment 76, 349-359.

Curran, P.J., Dungan, J.L., Macler, B.A., \& Plummer, S.E. (1991). The effect of a red leaf pigment on the relationship between red edge and chlorophyll concentration. Remote Sensing of Environment, 35, 69-76.

Isagi, Y. (1995). Plant resource budget model for masting. Bulletin of the society of population ecology, 52, 49-54.

Isagi, Y, Sugimura, K., Sumida, A. \& Ito, H. (1997). How does masting happen and synchronize? Journal of Theoretical Biology, 187, 231-239.

Jago, R.A., Cutler, M.E.J. \& Curran, P.J. (1999). Estimating canopy chlorophyll concentration from field and airborne spectra. Remote Sensing of Environment, 68 3, 217-224.

Keiner, L.E. \& Yan, X.H. (1998). A neural network model for estimating sea surface chlorophyll and sediments from thematic mapper imagery. Remote Sensing of Environment, 66, 153-165.

Mutanga, O. \& Skidmore, A. K. (2004). Integrating imaging spectroscopy and neural networks to map grass quality in the Kruger National Park, South Africa. Remote Sensing of Environment, 90(1), 104-115.

Noguchi, Y., Sakai, K.\& Asada, S. (2003). Reconstructed Dynamics of Alternate Bearing on Citrus Unsyu by 
Experimentally Estimated Jacobian and One year Forward Yield Prediction, Technical Report of IEICE, NLP2002-151.

Noguchi, Y., Sakai, k., Asada, S., Garciano, L \& Sasao, A. (2003). Modeling of alternate bearing in Satsuma Mandarin-Linear dynamic model based on ensemble dataset for harvested fruits number. Japanese Journal of Agricultural Engineering, 65(6), 55-61.

Ramadan, Z., Hopke, P. K., Johnson, M. J. \& Scow, K. M., (2004). Application of PLS and Back-Propagation Neural Networks for theestimation of soil properties. Chemometrics and Intelligence Laboratory Systems.

Sakai, K. (2001). Nonlinear dynamics and chaos in agricultural systems. Elsevier Science B.V., Netherlands, 59-77.

Sakai, K., Noguchi,Y. \& Asada, S. (2003). Nonlinear Dynamics in Arable land: Alternate Bearing of Tree Crops, Technical Report of IEICE, NLP, 2002-132.

Serrano, L., Filella, I. \& Penuelas, J.(2000). Remote sensing of biomass and yield of winter wheat under different nitrogen supplies. Crop Science, 40, 723-731.

Thenkabail, P.S., Smith, R.B. \& de Pauw, E. (2001). Hyperspectral vegetation indices and their relationships with agricultural crop characteristics. Remote Sensing of Environment, 71, 158-182.

Wiegand, C.L., Maas, S.J., Aase, J.K., Hatfield, J.L., Pinter, P.J., Jackson, R.D., Kanemasu, E.T., \& Lapitan, R.L. (1992). Multisite analyses of spectral-biophysical data for wheat. Remote Sensing of Environment, 42, 1-21.

Yoder, B.J. \& Waring, R.H. (1994). The normalized difference vegetation index of small douglas-fir canopies with varying chlorophyll concentrations. Remote Sensing of Environment, 49, 81-91.

Zhang, X., Li, C. \& Yuan, Y. (1997). Application of neural networks to identify vegetation types from satellite images. AI Applications, 11, 99-106.

Zhang, Y., Pulliainen, J., Koponen, S. \& Hallikainen, M. (2002). Application of an empirical neural network to surface water quality estimation in the gulf of Finland using combined optical data and microwave data. Remote Sensing of Environment, 81, 327-336.

Received Aug. 302005

Accepted Oct.20 2005

Environmental information. 


\title{
航空ハイパースペクトルイメージングによる 温州ミカン隔年結果のダイナミクスの解明
}

叶 旭君 ${ }^{1)}$ ・酒井憲司 $1^{*}$ ・浅田真一 2) ・ 秋田鉄也 ${ }^{1)}$ ・笹尾 彰 1$)$

1)東京農工大学農学部 $\bar{\top}$ 183-8509 東京都府中市幸町 3-5-8

2)神奈川県農業総合研究所 † 250-0024 小田原市根府川 574-1

\begin{abstract}
要旨
本研究では温州ミカン隔年結果現象の予測に資するため、航空ハイパースペクトルイメー ジングによる収量推定手法を検討した。2003 年 4 月、5 月および 6 月に神奈川試験場におい て実験果樹園の AIS A 航空ハイパースペクトルイメージを取得した。本研究の目的は、収量 推定のために, 適切な撮影時期と主要波長領域に関する知見を得ることである。相関係数分 析(CCA)、主成分分析 $(P C A)$ および部分最小二乗回帰(PLS)を用いて、得られた成分を入力 として、重線形回帰およびニューラル・ネットワーク・アルゴリズムによって、収量をモ デル化した。その結果、PLS 法が最有効であった。ニューラル・ネットワークモデルの安 定性について、統計的手法によってこれを検定した。また、撮影時期は 5 月が最も効果的 であった。

キーワード

リモートセンシング、ハイパースペクトルイメージイング、重線形回帰、ニューラル・ネッ トワーク・アルゴリズム、主成分分析(PCA)、部分最小二乗回帰(PLS)、ミカン
\end{abstract}

"Corresponding author. Tel/fax: +81-42-367-5755 E-mail: ken@cc.tuat.ac.jp (Kenshi Sakai) 